\title{
Comparision of Peri-Operative Findings between Proximal Laparoscopic Gastrectomyand Total Laparoscopic Gastrectomy for Proximal Gastric Cancer
}

\author{
Iqbal Masud Khan ${ }^{1 *}$, Md. Zakir Hossain ${ }^{2}$, Nishat Farhana Khan ${ }^{3}$, Nabaneeta Sarker ${ }^{4}$, Nayeem ${ }^{5}$ \\ ${ }^{1}$ Associate Professor, Dept. of Gastro Intestinal Laparoscopic Onco Surgery, MBBS, MS, MARKS Medical College \& Hospital, Dhaka, Bangladesh \\ ${ }^{2}$ Associate Professor and Classified Specialist, Dept. of Otolaryngology-Head \& Neck Surgery, MBBS, MCPS, DLO, FCPS, FACS (USA), FRCS \\ (Glasg), Central Medical Board and Combined Military Hospital, Dhaka Cantonment, Dhaka-1206, Bangladesh \\ ${ }^{3}$ Associate Professor, Dept. of Head (Community Medicine), MARKS Medical College \& Hospital, Dhaka, Bangladesh \\ ${ }^{4}$ Clinical Assistant, Dept. of Surgery, MARKS Medical College \& Hospital, Dhaka, Bangladesh \\ ${ }^{5}$ Registrar, Dept. of Surgery, MARKS Medical College \& Hospital, Dhaka, Bangladesh
}

DOI: $10.36348 /$ sjmps.2020.v06i04.003

| Received: 07.03.2020 | Accepted: 15.03.2020 | Published: 05.04.2020

*Corresponding author: Iqbal Masud Khan

\section{Abstract}

Introduction: Gastric Cancer is one of the major causes of cancer specific deaths worldwide and incidence of Proximal Gastric Cancer is increasing with time. Laparoscopic gastrectomy has increased in popularity in recent years due to lesser complications and higher functional preservation. Objective: To find out the Comparision of Peri-Operative Findings between Proximal Laparoscopic Gastrectomyand Total Laparoscopic Gastrectomy for Proximal Gastric Cancer. Methods: Between January 2018 and August 2019, a total of 77 patients underwent LPG with B1 reconstruction or LTG with Roux-en-Y (R-Y) reconstruction for gastric cancer in the proximl stomach in Marks medical College \& Hospital, Dhaka, Bangladesh. LPG was performed in 15 cases with tumor located in the upper third of the stomach. The resection line in the stomach was kept at least $5 \mathrm{~cm}$ apart from the gastric angle. On the other hand, LTG was performed in 57 cases of proximal gastric cancer. Results: In this study we have compared the peri-operative findings of 72 patients with proximal gastric cancers who underwent tumor excision surgery and were diveded into two groups according to different surgical approach; Laparoscopic Proximal Gastrectomy and Laparoscopic Total Gastrectomy. After statistical analysis, no significant differences were found in peri-operative outcomes between two groups. Prospective studies with larger sample size are required to validate the findings of this study. Conclusion: We found that there are no any significant differences in peri-operative findings between Laparoscopic Proximal Gastrectomy and Laparoscopic total gastrectomy surgical approach for proximal gastric cancer.

Keywords: Laparoscopic Proximal Gastrectomy; Laparoscopic Total Gastrectomy; Proximal Gastric Cancer.

Copyright @ 2020: This is an open-access article distributed under the terms of the Creative Commons Attribution license which permits unrestricted use, distribution, and reproduction in any medium for non-commercial use (NonCommercial, or CC-BY-NC) provided the original author and source are credited.

\section{INTRODUCTION}

Gastric cancer is the second leading cause of cancer specific mortality worldwide [1]. Japan and South Korea have highest incidence and prevalence gastric cancer. It is one of the most common malignant tumors in Bangladesh, whereas, Asia, Europe and America are regions with intermediate incidence. According to the evidences from the recent studies the 5 -year survival rate of gastric is increasing and the increased survival rate is attributed to earlier disease diagnosis due to screening programs and more aggressive surgical treatment [2]. Gastrectomy with regional lymphadenectomy is considered to be the most potential curative treatment available for early gastric cancer. Laparoscopic surgery is also called minimally invasive surgery (MIS). It is relatively new technique but already has been well incorporated in different types of surgeries along with gastrecomy for gastric cancer [3]. Laparoscopic gastrectomy was first reported in 1992 [4], and since then laparoscopy-assisted gastrectomy (LAG) has been carried out not only in distal gastrectomy, but also in proximal gastrectomy and total gastrectomy [5-7]. In recent years, minimallyinvasive and function-preserving surgery for treating proxima gastric cancer has gained populatiry among surgeons and become one of the general modalities to manage patients with early-stage gastric cancer [8]. Several recent small-sized, randomized clinical trial has suggested that the outcomes from laparoscopic surgery for all stages of gastric cancer were not inferior to those from open surgery [9]. Recently, minimally invasive 
approaches have been focusing in function-preserving surgeries (e.g., pylorus-preserving gastrectomy, proximal gastrectomy). Initially, pylorus-preserving gastrectomy (PPG) was used for gastric ulcers. This method has also been found to provide a better quality of life and oncologic safety when used for selected types of gastric cancer. Although total gastrectomy has been widely performed as standard surgery for proximal gastric cancer, proximal gastrectomy has recently been applied as a minimally invasive and function-preserving surgery for selected patients with proximal early gastric cancer. However, use of a laparoscopic approach for this procedure is difficult for inexperienced surgeons [10]. Whereas experienced surgeons have investigated, and reported on, various types of reconstruction methods and their technical feasibility after laparoscopic proximal gastrectomy [11]. In this study we have compared surgical outcomes and perioperative findings between patients undergoing LPG and LTG for proximal gastric cancer.

\section{ObJective}

To find out the Comparision of Peri-Operative Findings between Proximal Laparoscopic Gastrectomyand Total Laparoscopic Gastrectomy for Proximal Gastric Cancer.

\section{Patients And Methods}

Between January 2018 and August 2019, a total of 77 patients underwent LPG with B1 reconstruction or LTG with Roux-en-Y (R-Y) reconstruction for gastric cancer in the proximl stomach in Marks medical College \& Hospital, Dhaka, Bangladesh. LPG was performed in 15 cases with tumor located in the upper third of the stomach. The resection line in the stomach was kept at least $5 \mathrm{~cm}$ apart from the gastric angle. On the other hand, LTG was performed in 57 cases of proximal gastric cancer. Each tumor was histologically diagnosed as gastric adenocarcinoma, and was classified according to the Japanese classification of gastric carcinoma [12].

\section{Statistical Analysis}

Statistical analysis was performed using SPSS for Windows 19.0 to compare the peri-operative findings between LPG and LTG. Differences between Demographic Characteristics, intra-operative findings and post-operative findings along with short term complications were evaluated using the $\chi 2$ test.

\section{RESULTS \\ Demographic Characteristics}

Demographic Characteristics of patients are listed in [Table 1]. There were 13 males and 2 females in LPG group with Mean Age of $61.9 \pm 7.6$ years and Mean BMI of 23.9 \pm 4.2 . 7 patients had co-morbidity and 4 patients had undergone previous abdominal surgery. For LTG group there were 41 male patients and 16 female patients with Mean Age of 66.0 \pm 6.2 and Mean BMI of 22.9 \pm 3.1 .29 patients had co-morbidities and 18 patients had undergone previous abdominal surgery in this group.

Table-1: Characteristic of patients $(\mathrm{N}=77)$

\begin{tabular}{|c|c|c|c|}
\hline Variable & B-I $(\mathbf{n = 1 5})$ & Roux-en-Y(n=57) & P value \\
\hline Age(yr) & $61.9 \pm 7.6$ & $66.0 \pm 6.2$ & $0.034 / 0.241$ \\
\hline Gender & & & \\
\hline Male & 13 & 41 & \\
\hline Female & 2 & 16 & \\
\hline BMI $\left(\mathrm{kg} / \mathrm{m}^{2}\right)$ & $23.9 \pm 4.2$ & $22.9 \pm 3.1$ & 0.306 \\
\hline Comorbidity & 7 & 29 & 0.772 \\
\hline Previous abdominal surgery & 4 & 18 & 1.000 \\
\hline
\end{tabular}

\section{Pathological Findings}

The pathological findings in both groups are listed in [Table 2]. The Mean Tumor Size in LPG group was $2.9 \pm 1.4 \mathrm{~cm}$ and LTG group was $4.8 \pm 2.4 \mathrm{~cm}$ $(\mathrm{P}=0.004)$. Histopathological study demonstrated that there were 2 well differentiated adenocarcinoma in LPG group and 5 in LTG group. 9 cases were with moderately differentiated adenocarcinoma in LPG group and 31 cases in LTG group. Poorly differentiated adenocarcinoma was found in 4 cases of LPG group and 21 cases of LTG group. 
Table-2: Pathologic findings $(\mathrm{N}=77)$

\begin{tabular}{|c|c|c|c|}
\hline Variable & B-I $(\mathbf{n = 1 5})$ & Roux-en-Y $(\mathbf{n}=\mathbf{5 7})$ & P value \\
\hline Tumor size $(\mathrm{cm})$ & $2.9 \pm 1.4$ & $4.8 \pm 2.4$ & $0.004 / 0.690$ \\
\hline Histological type & & & \\
\hline Well diff & 2 & 5 & \\
\hline Moderately diff & 9 & 31 & \\
\hline Poorly diff & 4 & 21 & \\
\hline TNM stage & & & 0.242 \\
\hline IA & 1 & 6 & \\
\hline IB & 4 & 3 & \\
\hline IIA & 3 & 6 & \\
\hline IIB & 4 & 18 & \\
\hline IIIA & 2 & 9 & \\
\hline IIIB & 1 & 11 & \\
\hline IIIC & 0 & 4 & \\
\hline
\end{tabular}

Table-3: Surgical outcomes and postoperative courses $(\mathrm{N}=77)$

\begin{tabular}{|c|c|c|c|}
\hline Variable & B-I (n=15) & Roux-en-Y $(\mathbf{n = 5 7})$ & P value \\
\hline Operation time (min) & $253.7 \pm 56.1$ & $263.5 \pm 53.1$ & 0.530 \\
\hline Estimated blood loss (mL) & $187.3 \pm 105.8$ & $145.4 \pm 183.3$ & 0.400 \\
\hline Open conversion & 0 & 1 & 1.000 \\
\hline Time to first flatus (d) & $5.5 \pm 1.4$ & $5.8 \pm 1.8$ & 0.491 \\
\hline Time to first oral intake (d) & $8.7 \pm 6.8$ & $7.5 \pm 1.5$ & 0.195 \\
\hline Hospital stay (d) & $17.9 \pm 11.0$ & $15.2 \pm 7.3$ & 0.263 \\
\hline Postoperative complications & 3 & 11 & 1.000 \\
\hline
\end{tabular}

\section{Intra-operative and Post-operative Findings}

Intra- and post-operative findings are listed in [Table 3]. Among all cases in both groups there was one open conversion due to severe adhesion. There were no significant differences in volume of operation time $(\mathrm{P}=0.530)$, estimated blood loss $(\mathrm{P}=0.400)$, time to first flatus $(\mathrm{P}=0.491)$, time to first oral intake $(\mathrm{P}=0.195)$ and duration of post-operative hospital stay $(\mathrm{P}=0.263)$. Post-operative complications occurred in 3 cases in LPG group and 11 cases in LTG group. Pulmonary infection was the most common complication which occurred in 4 patients in LTG group. Incision site infection was second most common complication and occurred in 1 patient from LPG group and 2 patients in LTG group. Anastomotic fistula occurred in single patient from both groups. Among rest of the complications GERD occurred in 1 patient from LPG group and Myocardial Infarction in 1 patient, chylous fistula in 1 patient, post-operative psychosis in 1 patient and peritonitis in 1 patient from LTG group.

\section{DISCUSSION}

Gastric cancer is one of the most common causes of cancer-related death in the world and incidence of Proximal Gastric Cancer has been found in increasing trend [13]. In this study Demographic Characteristics of patients are listed. There were 13 males and 2 females in LPG group with Mean Age of $61.9 \pm 7.6$ years and Mean BMI of 23.9 \pm 4.2 .7 patients had co-morbidity and 4 patients had undergone previous abdominal surgery. For LTG group there were 41 male patients and 16 female patients with Mean Age of $66.0 \pm 6.2$ and Mean BMI of 22.9 \pm 3.1 .29 patients had co-morbidities and 18 patients had undergone previous abdominal surgery in this group. With the advancement in technology, minimally invasive surgery has become very popular in the field of surgery. These days, laparoscopic surgery has become mainstay of treatment for Gastric Cancer. The pathological findings in both groups are listed in this study. The Mean Tumor Size in LPG group was $2.9 \pm 1.4 \mathrm{~cm}$ and LTG group was $4.8 \pm 2.4 \mathrm{~cm} \quad(\mathrm{P}=0.004)$. Histopathological study demonstrated that there were 2 well differentiated adenocarcinoma in LPG group and 5 in LTG group. 9 cases were with moderately differentiated adenocarcinoma in LPG group and 31 cases in LTG group. Poorly differentiated adenocarcinoma were found in 4 cases of LPG group and 21 cases of LTG group in this study. This study Post-operative complications occurred in 3 cases in LPG group and 11 cases in LTG group. Pulmonary infection was the most common complication which occurred in 4 patients in LTG group. Incision site infection was second most common complication and occurred in 1 patient from LPG group and 2 patients in LTG group. Anastomotic fistula occurred in single patient from both groups. Among rest of the complications GERD occurred in 1 patient from LPG group and Myocardial Infarction in 1 patient, chylous fistula in 1 patient, post-operative psychosis in 1 patient and peritonitis in 1 patient from LTG group. In the present study, laparoscopic proximal gastrectomy and laparoscopic total gastrectomy surgical approach were used for proximal gastric cancer. LPG was used for smaller tumor size and was concentrated 
on preservation of as much organ as possible for the functional restoration. LTG was used for comparatively larger tumor size. The extent of lymph node dissection was D2 in both the groups. The major limitations for the study were the possible biases because of a retrospective study and the sample size was not large enough to identify all the differences in patient characteristics and surgical outcomes between two groups. We limited our study to comparison of intraoperative and short term post-operative findings due to non-compliance of patients for long-term follow up. The result of present study should be validated by prospective studies with larger sample size.

\section{Conclusion}

We found that there are no any significant differences in peri-operative findings between Laparoscopic Proximal Gastrectomy and Laparoscopic total gastrectomy surgical approach for proximal gastric cancer.

\section{AbBreviations}

MIS, Minimally Invasive Surgery; LPG, Laparoscopic Proximal Gastrectomy; LTG, Laparoscopic Total Gastrectomy; LAG, Laparoscopic Assisted Gastrectomy; PPG, Pylorus Preserving Gastrectomy

\section{REFERENCES}

1. Tang, H. N., \& Hu, J. H. (2015). A comparison of surgical procedures and postoperative cares for minimally invasive laparoscopic gastrectomy and open gastrectomy in gastric cancer. International journal of clinical and experimental medicine, 8(7), 10321.

2. Lianos, G. D., Bali, C. D., Glantzounis, G. K., Katsios, C., \& Roukos, D. H. (2014). BMI and lymph node ratio may predict clinical outcomes of gastric cancer. Future Oncology, 10(2), 249-255.

3. Kitano, S., Iso, Y., Moriyama, M., \& Sugimachi, K. (1994). Laparoscopy-assisted Billroth I gastrectomy. Surgical laparoscopy \& endoscopy, 4(2), 146-148.

4. Goh, P., Tekant, Y., Isaac, J., Kum, C. K., \& Ngoi, S. (1992). The technique of laparoscopic Billroth II gastrectomy. Surgical laparoscopy endoscopy, 2(3), 258-260.
5. Lee, S. W., Nomura, E., Bouras, G., Tokuhara, T., Tsunemi, S., \& Tanigawa, N. (2010). Long-term oncologic outcomes from laparoscopic gastrectomy for gastric cancer: a single-center experience of 601 consecutive resections. Journal of the American College of Surgeons, 211(1), 33-40.

6. Jeong, G. A., Cho, G. S., Kim, H. H., Lee, H. J., Ryu, S. W., \& Song, K. Y. (2009). Laparoscopyassisted total gastrectomy for gastric cancer: a multicenter retrospective analysis. Surgery, 146(3), 469-474.

7. Tanimura, S., Higashino, M., Fukunaga, Y., Kishida, S., Ogata, A., Fujiwara, Y., \& Osugi, H. (2007). Laparoscopic gastrectomy with regional lymph node dissection for upper gastric cancer. British Journal of Surgery: Incorporating European Journal of Surgery and Swiss Surgery, 94(2), 204-207.

8. Kim, H. H., Han, S. U., Kim, M. C., Hyung, W. J., Kim, W., Lee, H. J., ... \& Ryu, S. Y. (2014). Longterm results of laparoscopic gastrectomy for gastric cancer: a large-scale case-control and case-matched Korean multicenter study.

9. Huscher, C. G., Mingoli, A., Sgarzini, G., Sansonetti, A., Di Paola, M., Recher, A., \& Ponzano, C. (2005). Laparoscopic versus open subtotal gastrectomy for distal gastric cancer: fiveyear results of a randomized prospective trial. Annals of surgery, 241(2), 232.

10. Son, T., Kwon, I. G., \& Hyung, W. J. (2014). Minimally invasive surgery for gastric cancer treatment: current status and future perspectives. Gut and liver, 8(3), 229.

11. Kinoshita, T., Gotohda, N., Kato, Y., Takahashi, S., Konishi, M., \& Kinoshita, T. (2013). Laparoscopic proximal gastrectomy with jejunal interposition for gastric cancer in the proximal third of the stomach: a retrospective comparison with open surgery. Surgical endoscopy, 27(1), 146153.

12. Gastric, J. (1998). Japanese classification of gastric carcinoma-2nd English edition. Gastric cancer, 1(1), 10-24.

13. Jemal, A., Bray, F., Center, M. M., Ferlay, J., Ward, E., \& Forman, D. (2011). Global cancer statistics. CA: a cancer journal for clinicians, 61(2), 69-90. 